\title{
A re-examination of the enigmatic Russian tetrapod Phreatophasma aenigmaticum and its evolutionary implications
}

\author{
Neil Brocklehurst ${ }^{1}$ and Jörg Fröbisch ${ }^{1,2,3}$ \\ ${ }^{1}$ Museum für Naturkunde, Leibniz-Institut für Evolutions- und Biodiversitätsforschung, Invalidenstraße 43, \\ 10115 Berlin, Germany \\ ${ }^{2}$ Institut für Biologie, Humboldt-Universität zu Berlin, Invalidenstraße 110, 10115 Berlin, Germany \\ ${ }^{3}$ Evolutionary Studies Institute \& School of Geosciences, University of the Witwatersrand, Private Bag 3, \\ Johannesburg 2050, South Africa \\ Correspondence to: Neil Brocklehurst (neil.brocklehurst@mfn-berlin.de)
}

Received: 4 October 2016 - Revised: 31 January 2017 - Accepted: 3 February 2017 - Published: 21 February 2017

\begin{abstract}
Phreatophasma aenigmaticum is a mysterious tetrapod from the earliest middle Permian of Russia, represented by a single femur. At various times since its original description it has been considered a therapsid synapsid, a pelycosaurian-grade synapsid from the family Caseidae, and most recently a seymouriamorph amphibian. Using upto-date knowledge of the postcranial morphology and evolution of early synapsids, the specimen is re-evaluated and subjected to cladistic analysis. Seymouriamorph and therapsid affinities are rejected, and a caseid affinity is supported based on the deep intertrochanteric fossa; the widely spaced distal condyles; the short, robust femoral shaft; and the lack of a longitudinal ridge enclosing the posterior margin of the intertrochanteric fossa. When included in two cladistic matrices, the first a global analysis of basal synapsids and the second devoted to caseids, Phreatophasma is found to occupy a basal position within caseids, retaining plesiomorphic characters such as the lack of compression of the anterior condyle of the femur and the almost identical distal extent of the two condyles. The recognition of Phreatophasma as a basal caseid has great implications for the evolution and biogeography of this family. This is only the second example of a caseid from the palaeo-temperate region of Russia, and it is not closely related to the first (Ennatosaurus tecton), implying at least two distinct dispersal events from the palaeoequatorial to temperate latitudes. It also implies that a number of plesiomorphic characteristics of caseids, including small body size and a relatively long femur, were retained as late as the middle Permian, a time when caseids were otherwise represented by large herbivorous taxa.
\end{abstract}

\section{Introduction}

The early-middle Permian transition was a crucial period in the evolution of early synapsids. During the Cisuralian, terrestrial faunas were dominated by a paraphyletic grade of six synapsid families known as pelycosaurs. However, at the start of the Guadalupian these declined in diversity, possibly due to a mass extinction event (Sahney and Benton, 2008; Brocklehurst et al., 2013), and the Therapsida (the clade containing mammals) became more diverse and abundant. This transition coincides with a shift in the location of greatest sampling from the palaeoequatorial localities of North America and western Europe to the palaeo-temperate localities of South Africa and Russia. There is only a brief period of temporal overlap between the Russian and North American localities in the latest Kungurian and Roadian (Benton, 2012).

Two of the six pelycosaur families are known to have survived into the middle Permian and dispersed into the palaeotemperate latitudes. Species of Varanopidae are known from both Russia and South Africa (Dilkes and Reisz, 1996; Reisz et al., 1998; Modesto et al., 2011; Reisz and Modesto, 2007; Botha-Brink and Modesto, 2009), as late as the Pristerognathus Assemblage Zone (latest Capitanian) of the Karoo Supergroup (Modesto et al., 2011). Thus, Varanopidae represents not only the geologically longest living pelycosaur family but also the geographically most widespread. The second such family is Caseidae. Although this family was most diverse in the San Angelo and Chickasha formations of North America (Olson, 1962, 1965, 1968; Brocklehurst et al., 2013), a substantial species richness of caseids was recently 
also reported from Europe (Berman et al., 2004; Reisz et al., 2011; Romano and Nicosia, 2015; Spindler et al., 2015), and the Russian species Ennatosaurus tecton appears to have been quite abundant in the Mezen Faunal Complex (Efremov, 1956).

A possible second Russian caseid has been tentatively put forward: Phreatophasma aenigmaticum, from the middle Permian Golyusherma Group. First described as a therapsid from the family Phreatosuchidae (Efremov, 1954), it was reassigned to Caseidae by Olson (1962), although the lack of material made this assignment extremely uncertain. Phreatophasma is represented by only a single femur and has not received substantial attention since Olson's monograph on the family Caseidae (Olson, 1968). A brief note by Golubev (2000) cast doubt on its caseid affinities and suggested it might be a seymouriamorph, although no discussion of specific morphological characters was supplied.

Now, however, our knowledge of the postcranial morphology of early synapsids has substantially increased (Benson, 2012), as has our knowledge of the evolution and phylogeny of caseids (Reisz, 2005; Maddin et al., 2008; Reisz and Fröbisch, 2014; Spindler et al., 2015; Romano and Nicosia, 2015; Brocklehurst et al., 2016a). Thus, following a reexamination and phylogenetic analysis of the specimen, we are able to confirm the assignment of Phreatophasma to Caseidae.

\section{Systematic palaeontology}

Synapsida Osborn, 1903

Caseasauria Williston, 1912

Caseidae Williston, 1911

Phreatophasma aenigmaticum Efremov, 1954

Diagnosis: distinguished from other members of Caseidae by the lack of a prominent, rugose mound on the dorsal surface and by the almost identical distal extent of the condyles of the femur.

Holotype: PIN 294/25, right femur (Fig. 1). This specimen is a cast; the original has been lost.

Locality and horizon: Santagulov Mine, Bashkortostan Province, Russia. Golyusherma Subassemblage, early Kazanian age (Golubev, 2000), thought to be equivalent to the Roadian (Benton, 2012).

\section{Description}

Phreatophasma is thus far known only from a single right femur. The femur is small compared to those of other synapsid taxa known from the site, being only $62 \mathrm{~mm}$ long. The ventral surface of the shaft is heavily weathered, but the proximal and distal ends are better preserved. The femoral shaft is

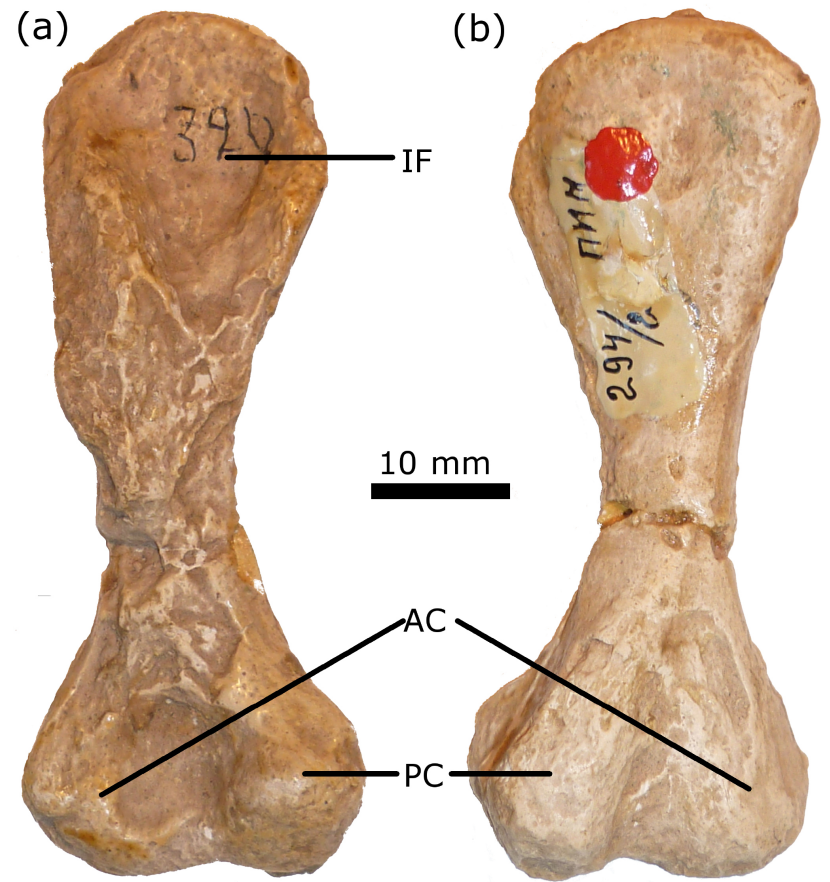

Figure 1. PIN 294/25, cast of the holotype of Phreatophasma aenigmaticum. (a) Ventral view; (b) dorsal view. Abbreviations: IF - intertrochanteric fossa, AC - anterior condyle, PC - posterior condyle.

straight, but in anterior view the proximal end may be seen to curve dorsally. The rugose mound present on the dorsal surface of the femur in many pelycosaurian-grade synapsids is low and smooth in Phreatophasma. The intertrochanteric fossa is deep and proximo-distally long. It does not appear to be enclosed distally by a longitudinal ridge, a morphology found in most caseids and also Dimetrodon. Unfortunately, due to the weathered surface, the morphology of the fourth trochanter cannot be determined, although what is preserved does appear to be large and prominent. Likewise, the prominence and extent of the adductor crest cannot be confirmed, although the distal end of the femur is well preserved enough to show that it did not reach far distally. The shaft of the femur is relatively short and robust, similar in proportion to Cotylorhynchus. The distal condyles are distinct and widely spaced and show almost no difference in their distal extent, unlike more derived caseids where the posterior condyle extends considerably further distally. The posterior condyle is extremely heavily built, similar in proportion to most caseids. The anterior condyle is dorso-ventrally more slender but does not exhibit the extreme compression observed in edaphosaurids and derived caseids. 


\section{Discussion}

\subsection{Caseid affinities of Phreatophasma}

Phreatophasma aenigmaticum has been assigned at various points in history to three different clades. In the original description, Efremov (1954) assigned it to the family Phreatosuchidae along with two other Russian genera: Phreatosuchus and Phreatosaurus. Phreatosuchidae are usually inferred to be therapsid synapsids, possibly of dinocephalian affinity (Olson, 1962; King, 1988; Ivakhnenko, 1991). However, Efremov (1954) acknowledged that Phreatophasma showed some similarities with edaphosaurid and caseid pelycosaurs. Olson (1962) suggested that Phreatophasma should be assigned to Caseidae, based on the dorsal inflection of the proximal end of the femur (giving, as he described it, a "sphinx-like" profile in anterior view), a deep intertrochanteric fossa, and the widely spaced distal condyles. Olson (1962) did add a note of caution to this assignment, acknowledging the scant material. In later summaries of pelycosaurian-grade synapsids and their evolution (e.g. Olson, 1968; Reisz, 1986; Brocklehurst et al., 2013), this assignment was repeated with the same advice of caution.

A third suggestion for Phreatophasma's affinity was made by Golubev (2000) in his summary of the faunal assemblages of the Permian terrestrial vertebrates in Russia. In this monograph, he assigned Phreatophasma to Leptorophinae, a subfamily of seymouriamorph amphibians. This assignment was justified in a brief footnote, noting that Phreatophasma closely resembled the femur of the seymouriamorph Kotlassia. The leptorophines, closely related to Kotlassia, are common in the copper mines where Phreatophasma was found. Unfortunately, Golubev (2000) did not actually state any of the characteristics that he felt united Phreatophasma with seymouriamorphs. Moreover, the femora of the two leptorophine taxa from Golyusherma (Biarmica and Leptoropha) are unknown, making a direct comparison impossible.

While Kotlassia's femur does share with Phreatophasma the broad proximal end flexed dorsally, in other respects there seem to be great differences. In general proportions, the taxa show few similarities; Kotlassia has a long, slender femoral shaft; the distal condyles are narrowly spaced; and the intertrochanteric fossa, though antero-posteriorly broad, is shallow (Bystrow, 1944). It is true that there is considerable variation in femoral proportions in seymouriamorphs; Seymouria itself had an extremely robust femur with a short shaft, that of Utegenia was short and dorsoventrally flattened, and the Russian leptorophines include forms with longer shafts and deeper intertrochanteric fossae (Kuhn, 1972; Klembara and Ruta, 2004). However, there are other reasons to reject a seymouriamorph affinity for Phreatophasma. The proximal and distal ends of its femur are heavily ossified, contrasting strongly with those of seymouriamorphs. The prominent separation of the bulbous dis-

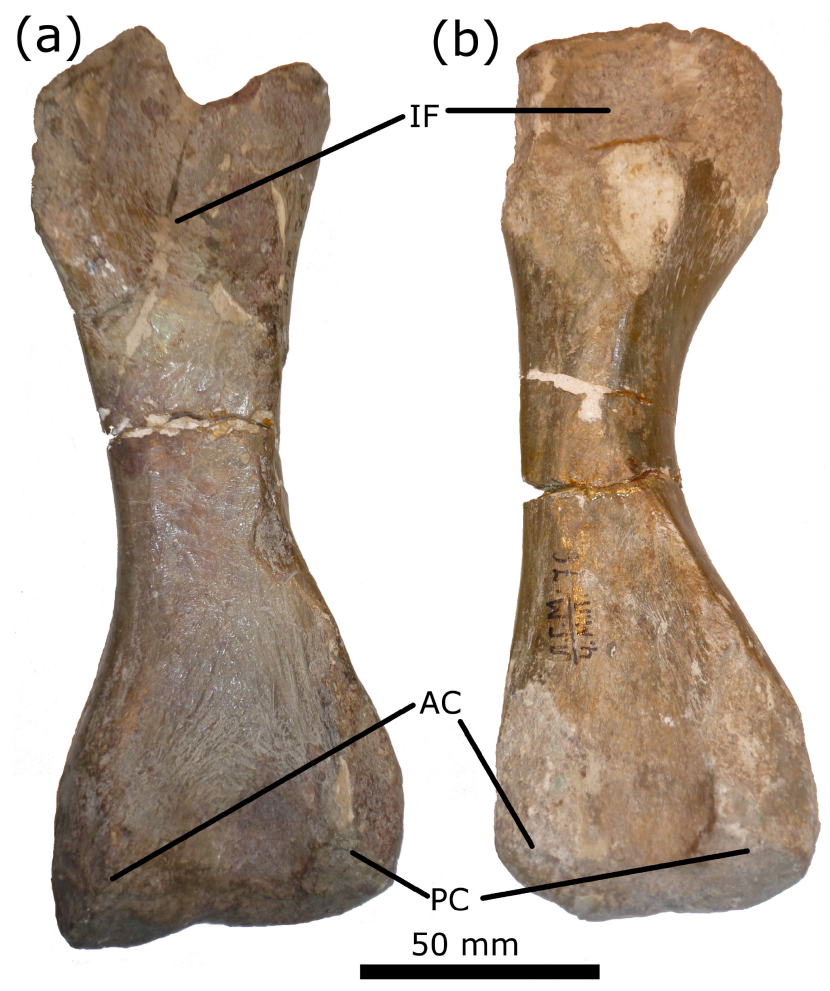

Figure 2. Two femoral specimens assigned to the therapsid clade Phreatosuchidae. (a) PIN 954/75, holotype of Phreatosaurus bazhovi; (b) PIN 1954/76, holotype of Phreatosuchus qualeni. Abbreviations as in Fig. 1.

tal condyles also conflicts strongly with seymouriamorphs, whose condyles are pressed close to each other as well as being more antero-posteriorly slender. Moreover, although the heavily weathered ventral surface of Phreatophasma does make comparison difficult, there is no evidence of the large and prominent adductor ridge that extends far distally, often onto the posterior condyle, in Kotlassia and the Russian seymouriamorphs.

A therapsid affinity is also rejected. The intertrochanteric fossae of therapsid femora are greatly reduced compared to pelycosaurs, while the distal condyles are low and indistinctly separated (Sidor and Hopson, 1998). These characters are seen in Phreatosuchus and Phreatosaurus (Fig. 2) but are absent in Phreatophasma. Instead, Phreatophasma is deemed to be a caseid, as judged by Olson (1962). Although the sphinx-like profile is not as strong a support of caseid affinity as was thought (it is also observed in edaphosaurids and several amphibian clades, including seymouriamorphs), the other characteristics cited above do support such an assignment. Also indicating a caseid affinity are the short, robust femoral shaft and the lack of a longitudinal ridge enclosing the posterior margin of the intertrochanteric fossa.

If Phreatophasma is indeed a caseid, it is necessary to compare it to the only other Russian caseid known: En- 
natosaurus tecton (Efremov, 1956) from the younger Mezen faunal complex. It is obvious that these taxa are not synonymous, and it appears unlikely that they are closely related beyond both being caseids. Although the Ennatosaurus femur studied represents a juvenile individual (PIN 1580/107) and Phreatophasma appears to be more advanced in its ontogeny due to the extensive ossification of the distal condyles, the femur of the juvenile Ennatosaurus is substantially larger. The rugose mound on the dorsal surface of the femur is considerably more prominent in Ennatosaurus than Phreatophasma, and the dorsal inflection of the proximal end is more pronounced in the former. Phreatophasma appears to be more plesiomorphic than Ennatosaurus, as its anterior condyle is not compressed and the posterior condyle does not extend considerably further distally than the anterior. A basal position within caseids might also be supported by the small size; caseids appear to have shown a trend towards increased body size during their evolution (Reisz and Fröbisch, 2014).

\subsection{Phylogenetic analysis}

In order to test the relationships of Phreatophasma, the specimen was incorporated into two phylogenetic analyses: the first was a global analysis of pelycosaurian-grade synapsids in order to confirm the caseid affinity, and the second was an analysis devoted to caseids, containing a wider sampling of caseid taxa. For the first of these analyses, Phreatophasma was added to the matrix of Brocklehurst et al. (2016b). This matrix is an expanded version of that of Benson (2012), who incorporated a larger number of postcranial characters than had previously been considered. At present, this matrix represents the most comprehensive examination of pelycosaur relationships, both in terms of character and taxon sampling. The matrix was analysed in TNT version 1.5 (Goloboff et al., 2008), using the new technology-driven search at level 100. The minimum length was searched 100 times using the drift, fusion, and sectorial search algorithms. Each most parsimonious tree found using this search was then used as the starting tree in a branch and bound search. Node support was calculated using the relative fit difference (Goloboff and Farris, 2002).

The analysis identified 1920 most parsimonious trees of a length of 785 and retention index of 0.74 , with very little resolution within caseids. After removing the wildcard taxon Caseopsis agilis, 361 trees remained, with considerably better resolution in this family. Phreatophasma was found to occupy a basal position within Caseidae (Fig. 3), in a polytomy with Datheosaurus, Oromycter, and the clade containing Casea broilii and all caseids more derived. Although a caseid affinity for Phreatophasma is well supported, its precise position within Caseidae is not as well supported, which is unsurprising given the completeness of the specimen. Its position in a clade containing all caseids except for Callibrachion and Eocasea is based on the lack of the ridge enclosing the posterior margin of the intertrochanteric fossa. Its more

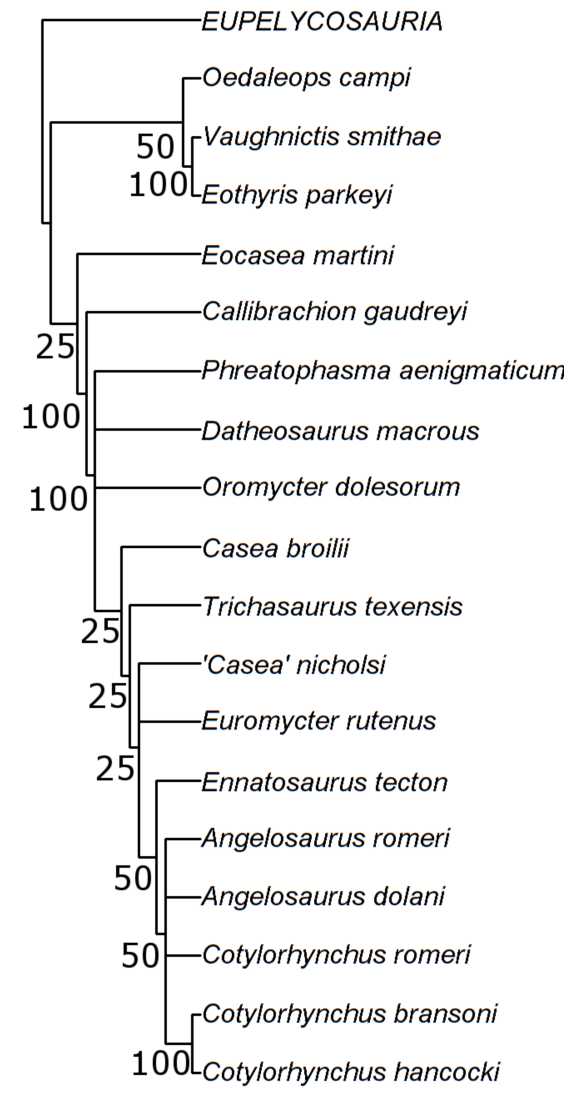

Figure 3. Relationships of caseids found by adding Phreatophasma to the matrix of Brocklehurst et al. (2016b) after removing the wildcard taxon Caseopsis. Relationships within Eupelycosauria are identical to those found by Brocklehurst et al. (2016b).

basal position than Casea broilii is indicated by the femoral condyles having very similar distal extents and by the lack of compression of the anterior condyle. It should be noted, however, that the latter character appears to be somewhat plastic, being reversed (uncompressed) in more derived taxa such as Casea nicholsi, Caseopsis, and Ruthenosaurus.

Phreatophasma was also added to the matrix of Romano and Nicosia (2015), who analysed caseid relationships using a mixture of discrete characters and what they termed morphometric characters (ratios of linear measurements treated as continuous characters). Also added to this matrix was Vaughnictis smithae (formerly Mycterosaurus smithae), recently redescribed as an eothyridid caseasaur (Brocklehurst et al., 2016b), in order to add some postcranial data from this family. Two separate analyses were carried out using this dataset. First the morphometric characters were analysed unaltered as continuous characters in TNT. Each morphometric character was scaled from 0 to 65 (the minimum and maximum values allowed in TNT), and the discrete characters were weighted at 65 to allow for the reduced possible num- 
ber of character changes. The matrix was analysed in TNT using the same settings described above.

The second analysis using the Romano and Nicosia matrix followed the suggestion of Brocklehurst et al. (2016a). The ratios were first transformed using the log-ratio method (Aitchison, 1986) and were then subjected to a principal component analysis in order to reduce issues of redundancy and character non-independence. The principal component scores were treated as continuous characters (hereafter these characters are referred to as PC characters). The log-ratio transformations were carried out in $\mathrm{R}$ version 3.03 ( $\mathrm{R}$ core team, 2013) using functions from the packages robCompositions (Templ et al., 2011), and the principal component analysis was carried out in Past 3.11 (Hammer et al., 2001) using the iterative imputation method to treat missing values. The PC characters were scaled in the manner described by Brocklehurst et al. (2016a) so that each contained values between 0 and 65 , and the relative variances of the PC characters were equal to the relative variances of the principal coordinates.

Both analyses using the Romano and Nicosia (2015) dataset supported the global pelycosaur analysis in finding Phreatophasma in a basal position within caseids (Fig. 4). Again, in both analyses, support for a monophyletic Caseidae containing Phreatophasma is high, but support for its precise position is low. Each found three most parsimonious trees, the first of length 42883.237 and the second of 1434.131, and in the strict consensus Phreatophasma resides in a polytomy with Oromycter, "Casea" halselli, and the clade containing all other caseids. The positions of "Casea" halselli as a basal caseid is novel, although it should be noted that this is an extremely incomplete taxon and its position in the phylogeny has been highly unstable in previous analyses (Romano and Nicosia, 2015; Brocklehurst et al., 2016a). Unfortunately the limited overlap between the preserved elements of Phreatophasma, Oromycter, and "Casea" halselli limits the possible resolution at the base of Caseidae.

In addition to the discrete characters described above, the morphometric characters add further information. The characters supporting a basal position of Phreatophasma include a lower value for the ratio of the anterior condyle width and total femur length than more derived caseids, i.e. Phreatophasma either has a longer femur or a narrower anterior condyle. This is supported by the phylogenetic analysis using PC characters; Phreatophasma has a lower value of PC character 12 than more derived caseids. This PC character is heavily loaded towards, among other things, ratios indicating a relatively longer femur in Phreatophasma but with wider proximal and distal heads and shaft.

\subsection{Evolution of Caseidae}

The phylogenetic analyses including Phreatophasma have some important implications for caseid evolution and biogeography. The basal position of Phreatophasma, far from that of Ennatosaurus, indicates that there were at least two
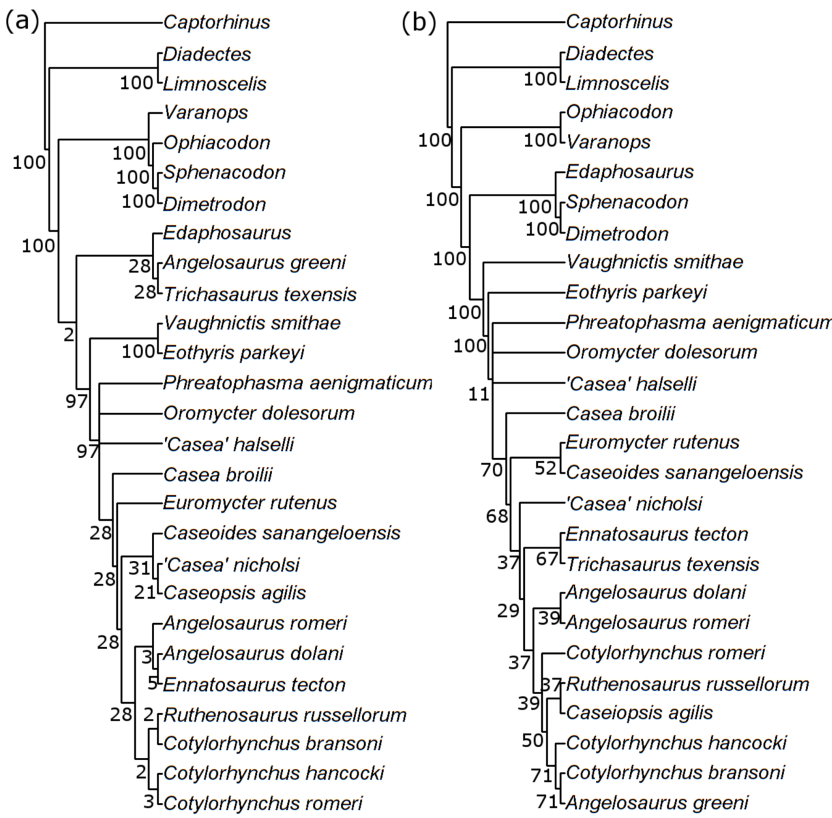

Figure 4. Relationships of caseids found by adding Phreatophasma to the matrix of Romano and Nicosia (2015). (a) Continuous characters represent morphometric characters of Romano and Nicosia (2015). (b) Continuous characters represent PC characters of Brocklehurst et al. (2016a).

dispersal events between the palaeoequatorial and palaeotemperate latitudes in this family (Fig. 5). This, combined with the fact that the European taxa are widely dispersed through the tree rather than forming a closely related grouping, implies relatively free dispersal between the different environments. Although Phreatophasma is of Roadian age, its position in the phylogeny implies a ghost lineage extending at least as far back as the early Artinskian, and possibly even earlier depending on its precise position (Fig. 5). The position of Ennatosaurus also implies a ghost lineage extending back into the early Permian, although not as far. It is unfortunate that we have no knowledge of the Russian terrestrial vertebrate faunas prior to the Kungurian, meaning that the precise timing of the caseid invasions and their abundance prior to the diversification of therapsids is unknown.

The phylogenetic analyses also imply the survival of a broader range of taxa into the middle Permian than previously thought. Earlier examinations indicated that the taxa that crossed the Kungurian-Roadian boundary were all large, derived herbivores (Benton, 2012; Brocklehurst et al., 2013). However, Phreatophasma demonstrates that small basal caseids were also able to survive into the middle Permian. The taxa most closely related to Phreatophasma, such as Datheosaurus and Oromycter, seem to have represented medium-sized omnivores or carnivores (Reisz, 2005; Reisz and Fröbisch, 2014; Spindler et al., 2015) rather than highfibre herbivores. The confirmation of Phreatophasma's ca- 


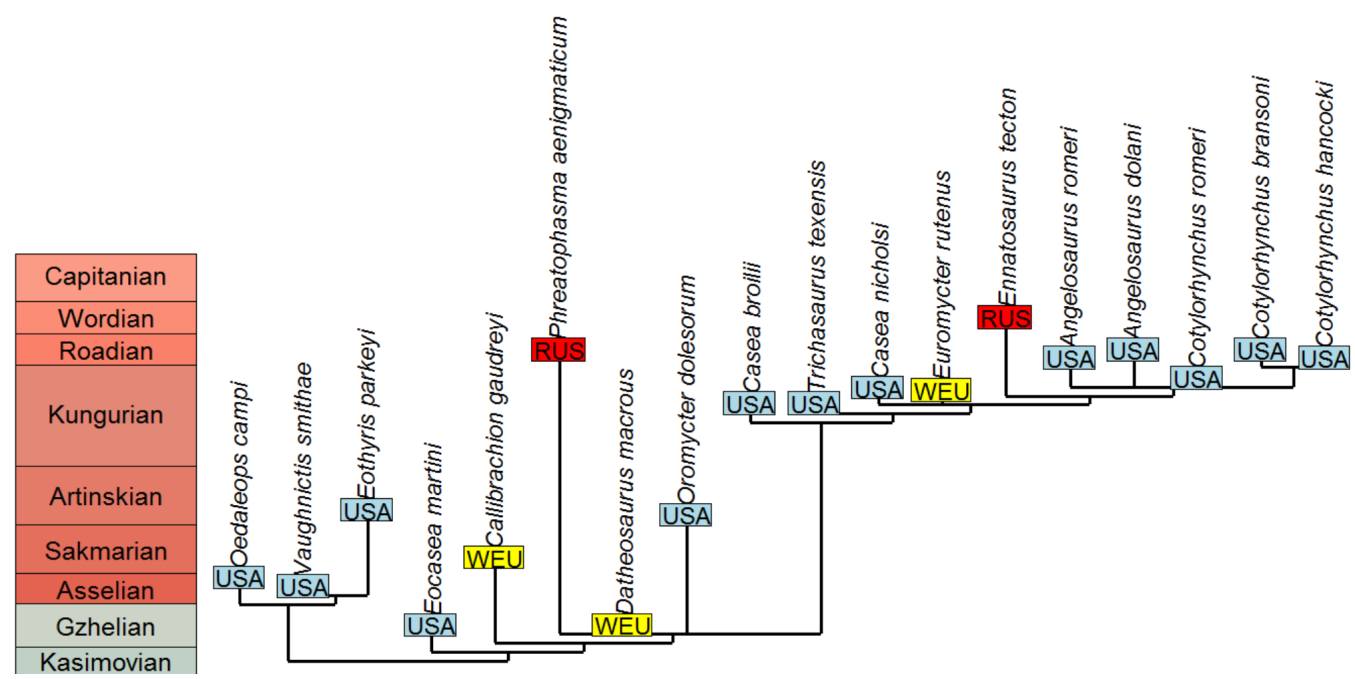

Figure 5. Distribution of caseids through time and space. Tip labels represent geographic location. Abbreviations: WEU - western Europe; RUS - Russia; USA - the United States of America.

seid affinity implies that middle Permian caseids were not only more speciose than other pelycosaur clades (Brocklehurst et al., 2013) but were also more morphologically diverse.

\section{Data availability}

All necessary data are available in the supplement.

\section{The Supplement related to this article is available online at doi:10.5194/fr-20-87-2017-supplement.}

Competing interests. The authors and editor F. Witzmann work at the same institution but do not collaborate scientifically, and the paper was accepted on the basis of reviews from two outside reviewers. The authors declare no other competing interests.

Acknowledgements. We would like to thank the Palaeontological Institute of Moscow for access to their specimens, and in particular Valery Golubev for his assistance during our visit. Roger Benson, Marco Romano, Robert Reisz, and Christian Kammerer provided many helpful comments and discussion. Hillary Maddin and Andrej Cernansky provided constructive reviews of the early draft of the paper. This study was funded by a Deutsche Forschungsgemeinschaft grant (number FR 2457/5-1) awarded to Jörg Fröbisch.

Edited by: F. Witzmann

Reviewed by: H. Maddin and A. Cernansky

\section{References}

Aitchison, J.: The Statistical Analysis of Compositional Data, Chapman \& Hall, London, 1986.

Benson, R. B. J.: The global interrelationships of basal synapsids: cranial and postcranial morphological partitions suggest different topologies, J. Syst. Palaeontol., 10, 601-624, 2012.

Benton, M. J.: No gap in the Middle Permian record of terrestrial vertebrates, Geology, 40, 339-342, 2012.

Berman, D. S., Henrici, A. C., Kissel, R. A., Sumida, S. S., and Martens, T.: A new diadectid (Diadectomorpha), Orobates pab$s t i$, from the Early Permian of central Germany, Bulletin of the Carnegie Museum of Natural History, 35, 1-36, 2004.

Botha-Brink, J. and Modesto, S. P.: Anatomy and relationships of the Middle Permian varanopid Heleosaurus scholtzi based on a social aggregation from the Karoo Basin of South Africa, J. Vertebr. Paleontol., 29, 389-400, 2009.

Brocklehurst, N., Kammerer, C. F., and Fröbisch, J.: The early evolution of synapsids, and the influence of sampling on their fossil record, Paleobiology, 39, 470-490, 2013.

Brocklehurst, N., Ruta, M., Müller, J., and Fröbisch, J.: Elevated extinction rates as a trigger for diversification rate shifts: early amniotes as a case study, Scientific Reports 5, 17104, 2015.

Brocklehurst, N., Romano, M., and Fröbisch, J.: Principal Component Analysis as alternative treatment for morphometric characters: phylogeny of caseids as a case study, Palaeontology, 59, 877-886, 2016a.

Brocklehurst, N., Reisz, R. R., Fernandez, V., and Fröbisch, J.: A re-description of "Mycterosaurus" smithae, an early Permian eothyridid, and its impact on the phylogeny of pelycosaurian-grade synapsids, Plos One, 11, e0156810, doi:10.1371/journal.pone.0156810, 2016b.

Bystrow, A. P.: Kotlassia prima Amalitzky, Bull. Geol. Soc. Am., 55, 379-416, 1944.

Dilkes, D. W. and Reisz, R. R.: First record of a basal synapsid ("mammal-like reptile") in Gondwana, P. Roy. Soc. B-Biol. Sci., 263, 1165-1170, 1996. 
Efremov, I. A.: The fauna of terrestrial vertebrates in the Permian copper sandstones of the western Cis-Urals. Transactions of the Paleontological Institute, Academy of Science USSR, 56, 1-146, 1954.

Efremov, I. A.: American elements in the fauna of the USSR, Doklady AN SSSR 111, 1956.

Goloboff, P. A. and Farris, J. S.: Methods for quick concensus estimation, Cladistics, 17, S26-S34, 2002.

Goloboff, P. A., Farris, J. S., and Nixon, K. C.: TNT, a free program for phylogenetic analysis, Cladistics, 24, 774-778, 2008.

Golubev, V.: The faunal assemblages of Permian terrestrial vertebrates from Eastern Europe, Paleontol. J., 34, 211-224, 2000.

Hammer, O., Harper, D. A. T., and Ryan, P. D.: Past: paleontological statistics software package for education and data analysis, Palaeontol. Electron., 4, 1-9, 2001.

Ivakhnenko, M. F.: Elements of the early Permian tetrapod assemblages of Eastern Europe, Palaeontol. J., 24, 104-112, 1991.

King, G. M.: Anomodontia, Gustav Fischer Verlag, Stuttgart, New York, 1988.

Klembara, J. and Ruta, M.: The seymouriamorph tetrapod Utegenia shpinari from the ?Upper Carboniferous-Lower Permian of Kazakhstan. Part II: Postcranial anatomy and relationships. Eart and Evironmental Science Transactions of the Royal Society of Edinburgh, 95, 75-93, 2004.

Kuhn, O.: Batrachosauria (Anthracosauria), Gustav Fischer Verlag, Stuttgart, New York, 1972.

Maddin, H. C., Sidor, C. A., and Reisz, R. R.: Cranial anatomy of Ennatosaurus tecton from the Middle Permian of Russia and the evolutionary relationships of Caseidae, J. Vertebr. Paleontol., 28, 160-180, 2008.

Modesto, S., Smith, R. M. H., Campione, N. E., and Reisz, R. R.: The last "pelycosaur": a varanopid synapsid from the Pristerognathus Assemblage Zone, Middle Permian of South Africa, Naturwissenschaften, 98, 1027-1034, 2011.

Olson, E. C.: Late Permian terrestrial vertebrates, USA and USSR, T. Am. Philos. Soc., 52, 1-224, 1962.

Olson, E. C.: New Permian vertebrates from the Chickasha Formation in Oklahoma, Oklahoma Geological Survey, 70, 1-70, 1965.

Olson, E. C.: The family Caseidae. Fieldiana, Geology, 17, 225349, 1968.

R Core Team: R: A language and environment for statistical computing, R Foundation for Statistical Computing, Vienna, Austria, 2013.
Reisz, R. R.: Pelycosauria, Gustav Fischer Verlag, Stuttgart, Stuttgart, New York, 1986.

Reisz, R. R.: Oromycter, a new caseid from the Lower Permian of Oklahoma, J. Vertebr. Paleontol., 25, 905-910, 2005.

Reisz, R. R. and Fröbisch, J.: The oldest caseid synapsid from the Late Pennsylvanian of Kansas, and the evolution of herbivory in terrestrial vertebrates, Plos One, 9, e94518, doi:10.1371/journal.pone.0094518, 2014.

Reisz, R. R. and Modesto, S. P.: Heleosaurus scholtzi from the Permian of South Africa: a varanopid synapsid, not a diapsid reptile, J. Vertebr. Paleontol., 27, 734-739, 2007.

Reisz, R. R., Dilkes, D. W., and Berman, D. S.: Anatomy and relationships of Elliotsmithia longiceps Broom, a small synapsid (Eupelycosauria: Varanopseidae) from the Late Permian of South Africa, J. Vertebr. Paleontol., 18, 602-611, 1998.

Reisz, R. R., Maddin, H. C., Fröbisch, J., and Falconnet, J.: A new large caseid (Synapsida, Caseasauria) from the Permian of Rodez (France), including a reappraisal of "Casea” rutena SigogneauRussell \& Russell, 1974, Geodiversitas, 88, 227-246, 2011.

Romano, M. and Nicosia, U.: Cladistic analysis of Caseidae (Caseasauria, Synapsida): using the gap-weighting method to include taxa based on incomplete specimens, Palaeontology, 58, 1109-1130, 2015.

Sahney, S. and Benton, M. J.: Recovery from the most profound mass extinction of all time, P. Roy. Soc. B, 275, 759-765, 2008.

Sidor, C. A. and Hopson, J. A.: Ghost lineages and "mammalness": assessing the temporal pattern of character acquisition in the Synapsida, Paleobiology, 24, 254-273, 1998.

Spindler, F., Falconnet, J., and Fröbisch, J.: Callibrachion and Datheosaurus, two historical and previously mistaken basal caseasaurian synapsids from Europe, Acta Paleontologic Polonica, 61, 597-616, 2015.

Templ, M., Hron, K., and Filzmoser, P.: robCompositions: an R package for robust statistical analysis of compositional data, in: Compositional Data Analysis: Theory and Applications, 341356, edited by: Pawlowski-Glahn, V. and Buccianti, A., Wiley, West Sussex, 2011.

Williston, S. W.: American Permian Vertebrates, University of Chicago Press, Chicago, 1911.

Williston, S. W.: Primitive reptiles. A review, J. Morphol., 23, 637666, 1912. 